Relato de Caso

\title{
Óbito após transplante de fígado esquistossomótico
}

Case report: Death after schistosomic liver transplantation

Talita Zerbini(1), Sheila A.C. Siqueira(2)

Zerbini T, Siqueira SAC. Relato de caso: Óbito após transplante de fígado esquistossomótico. Saúde, Ética \& Justiça. 2010;15(2):80-3.

RESUMO: A hepatite aguda fulminante está entre as principais indicações de transplante de fígado. No presente artigo, relatamos o exame necroscópico de uma puérpera que apresentou essa complicação, falecendo no $2^{\circ}$ dia do pós-operatório do transplante. A análise histopatológica do fígado doador revelou acometimento do órgão por esquistossomose. De acordo com o protocolo utilizado no Estado de São Paulo, a pesquisa de esquistossomose nos órgãos do doador não é obrigatória, cabendo à equipe de transplante decidir sobre a aceitação ou recusa do órgão no caso de suspeita.

DESCRITORES: Hepatite; Metildopa; Falência hepática aguda; Transplante de fígado; Esquistossomose.

\footnotetext{
1. Especialista em Medicina Legal junto ao Departamento de Medicina Legal, Ética Médica e Medicina Social e do Trabalho da Faculdade de Medicina da Universidade de São Paulo.

2. Médica assistente do Hospital das Clínicas da Faculdade de Medicina da Universidade de São Paulo.

Endereço para correspondência: Faculdade de Medicina da Universidade de São Paulo - Instituto Oscar Freire. Av. Doutor Arnaldo, 455 Cerqueira César, São Paulo/SP. CEP 01246-903.
} 
Zerbini T, Siqueira SAC. Relato de caso: Óbito após transplante de fígado esquistossomótico.

\section{INTRODUÇÃO}

$\mathrm{O}$ transplante de fígado é considerado o procedimento mais complexo da cirurgia moderna, uma vez que nenhum outro interfere com tantas funções do organismo ${ }^{1}$. Tem evoluído ao longo dos últimos anos, firmando-se como única opção terapêutica eficaz no tratamento de algumas doenças hepáticas avançadas².

A Política Nacional de Transplantes de Órgãos e Tecidos está fundamentada nas Leis no 9.434/1997 e 10.211/2001, tendo como diretrizes a gratuidade da doação, a beneficência em relação aos receptores e não maleficência em relação aos doadores vivos. O número de transplantes de órgãos realizados no Brasil no $1^{\circ}$ semestre de 2009 foi de 8192, entre coração, córnea, fígado/rim, pulmão, rim, fígado, pâncreas e pâncreas/rim, segundo dados divulgados pelo Ministério da Saúde. Do total de procedimentos, $7,4 \%$ foram transplantes de fígado, ou seja, 606 órgãos transplantados. A taxa permanece bem abaixo do necessário, uma vez que a lista de espera em 2009 para esse tipo de transplante era de 4304 pessoas $^{3}$.

As principais indicações para a realização do transplante hepático são cirrose biliar primária, colangite esclerosante primária, atresia de vias biliares, hepatite crônica auto-imune e insuficiência hepática aguda grave, também chamada de "hepatite fulminante" ${ }^{\prime 4-6}$.

No presente artigo, relatamos o exame necroscópico de uma puérpera com quadro de hepatite aguda fulminante medicamentosa, submetida a transplante de fígado que faleceu no $2^{\circ}$ dia do pós-operatório devido a coagulopatia decorrente de insuficiência hepática aguda. A análise histopatológica do fígado doador revelou tecido com esquistossomose. O objetivo do trabalho é discutir se há interferência dessa doença na ocorrência de rejeição aguda do órgão transplantado.

\section{CASO}

\section{Histórico}

M.L.A.P, 34 anos, sexo feminino, primípara, cor parda, com história de descontrole pressórico após o sétimo mês de gestação, mantendo níveis acima de $170 \times 110 \mathrm{mmHg}$. Fez uso então de alfametildopa $250 \mathrm{mg}$ quatro vezes ao dia até a data do parto, que transcorreu sem intercorrências. Após o parto, a puérpera manteve os níveis pressóricos ao redor de $140 \times 90 \mathrm{mmHg}$ continuando com o mesmo medicamento na dose de $250 \mathrm{mg}$ duas vezes ao dia. Após três meses do parto, evoluiu com icterícia em escleras e pele, e alteração do nível de consciência, sendo levada ao Pronto-Socorro, onde foi feito diagnóstico de encefalopatia hepática grau II-III devido a hepatite aguda fulminante medicamentosa por alfa-metildopa, por não haver outra causa para a falência do órgão. Um dia após sua admissão na emergência foi transferida para a UTI de outro hospital para realização de transplante hepático. No $2^{\text {o }}$ dia de pós-operatório apresentou instabilidade hemodinâmica, sendo constatado óbito após algumas horas.

\section{Exame necroscópico}

A necrópsia foi realizada no Departamento de Patologia da Faculdade de Medicina da Universidade de São Paulo. O exame externo evidenciou icterícia 3+/4+em pele e esclera, ferida operatória recente tipo Mercedes, punção venosa em membros superiores e acesso venoso central em jugular direita. Ao exame interno, o fígado pesou $1330 \mathrm{~g}$ e estava pálido, ligeiramente endurecido aos cortes, com anastomose do enxerto íntegra e sinais de trombose venosa. Os rins estavam pálidos, o parênquima pulmonar encontrava-se friável em ambas as bases, e o endométrio, ovários, intestino delgado e intestino grosso com aspecto hemorrágico. A declaração de óbito foi emitida tendo como causa básica hepatite aguda fulminante medicamentosa e final choque hipovolêmico secundário a coagulopatia.

O exame microscópico evidenciou necrose tubular aguda, área de necrose focal em pâncreas, infarto de supra-renal direita e focos de broncopneumonia com hemorragia alveolar intensa. A análise do fígado do receptor (biópsia do explante) mostrou necrose hepática maciça hepatite fulminante, enquanto o fígado do doador (implante) mostrou lesão de preservação grau 2 com frequentes corpos apoptóticos e leve infiltrado neutrofílico sinusoidal, havendo obstrução de boa parte dos ramos venosos portais, granulomas portais com ovo não viável de Schistossoma $s p$ e raros nódulos hialinizados, que podem ter sido granulomas antigos, além de discreta fibrose periportal em alguns espaços porta, consistente com esquistossomose hepática.

\section{DISCUSSÃo}

A hipertensão arterial presente na gravidez é a causa de morte materna mais freqüente no Brasil atualmente $e^{7-9}$. A doença pode ser anterior à gravidez (Hipertensãoessencial), ser decorrente dela (Doença Hipertensiva Específica da Gestação - DHEG) ou ser a somatória das duas (Doença Hipertensiva Específica da Gestação superajuntada). A DHEG é 
resultado da má adaptação do organismo materno à atual situação ${ }^{10}$.

Os principais medicamentos utilizados para controle pressórico durante a gravidez são os bloqueadores de canal de cálcio, beta-bloqueadores e bloqueadores adrenérgicos de ação central, sendo a alfa-metildopa a principal representante desse grupo ${ }^{11}$. Seu efeito está na diminuição da resistência vascular sistêmica, sem alterações no débito cardíaco. É a droga mais utilizada no mundo para o controle de hipertensão arterial gestacional, tendo como efeito colateral mais grave a hepatite aguda, que ocorre em menos de $1 \%$ dos casos, sendo a evolução para hepatite fulminante menor que $2,5 \%$ destes casos $^{12}$.

A toxicidade da alfa-metildopa está relacionada a defeito da enzima citocromo P450 associada à reação imune exacerbada ao produto do metabolismo hepático. A hepatotoxicidade pela droga na gestação é evento extremamente raro, existindo apenas um relato de caso nos EUA em 20 anos (1976-1996).

A ocorrência de hepatite aguda fulminante é indicação de transplante hepático, apresentando altas taxas de mortalidade ${ }^{12}$.

O transplante de fígado pode produzir rejeição celular aguda de natureza humoral em $30 \%$ a $70 \%$ dos casos, especialmente nas primeiras duas semanas após o transplante, mas ela pode ocorrer em qualquer época após o procedimento². A maior incidência desse tipo de falência ocorre nos primeiros 7 a 10 dias pós-transplante ${ }^{12}$.

No caso em tela, o órgão implantado apresentava sinais de comprometimento por esquistossomose, inclusive com a presença de ovos de Schistosoma sp. De acordo com o protocolo da Secretaria de Estado da Saúde de São Paulo, a pesquisa de esquistossomose nos órgãos do doador não é obrigatória. No histórico dos doadores são levantados dados sobre região de origem do doador. Se proveniente de área endêmica para esquistossomose, a aceitação ou recusa do órgão fica a critério da equipe de transplante ${ }^{13}$.

A esquistossomose é endêmica em várias partes do mundo, gerando morbidade crônica em
200 a 250 milhões de pessoas no mundo. No Brasil, foi estimado, em 1997, que $5,2 \%$ da população era portadora da doença ${ }^{14}$. O dano ao órgão pode ser imunomediado, mas também pode ser decorrente da toxicidade direta do ovo do Schistosoma ${ }^{15}$. Havendo a toxicidade direta pela presença dos ovos, é possível que a reação celular e humoral aguda pelo organismo receptor seja exacerbada, o que levaria a aumento da probabilidade de rejeição ao transplante. Não há estudos publicados que discutam a influência sobre o prognóstico dos pacientes que receberam fígados com ovos de Schistossoma sp.

Há apenas um relato de caso na literatura de óbito após transplante de fígado esquistossomótico, que ocorreu na França. Porém, não há descrição a respeito da ocorrência ou ausência de rejeição do órgão transplantado ${ }^{16}$.

A grande maioria dos pacientes com esquistossomose não apresenta sintomas, devendo fazer seguimento com biópsia hepática anual para detecção precoce de eventuais complicações da doença².

Como a maioria dos casos de morte póstransplante hepático não são necropsiados por já contarem com diagnóstico bem estabelecido da causa da morte, a prevalência de órgãos acometidos pela esquistossomose pode ser subestimada, já que sua pesquisa prévia ao transplante no Brasil não é obrigatória.

\section{CONSIDERAÇÕES FINAIS}

O implante de fígado com esquistossomose pode levar à exacerbação da reação imune, o que aumentaria a incidência de rejeição celular aguda e possivelmente humoral nos órgãos implantados. $O$ caso relatado indica que é necessário pesquisar a influência dos ovos do Schistosoma sobre a rejeição do órgão pelo fígado receptor.

Com a oferta de órgãos abaixo do necessário para atender à lista de espera no Brasil, a determinação do risco de um transplante de fígado comprometido por esquistossomose cabe exclusivamente à equipe médica responsável.

Zerbini T, Siqueira SAC. Case report: Death after schistosomic liver transplantation. Saúde, Ética \& Justiça. 2010;15(2):80-3.

ABSTRACT: Fulminant hepatic failure is one of the principle indication for liver transplantation. In the present article, we report a necroscopic exam of a woman who presented that complication and died on the second day after transplant. Histopathology revealed that the donated liver had Schistosomiasis. According to the protocol used in the State of São Paulo, the screening for Schistosomiasis at the donated organ is not mandatory, being the transplant group responsible to decide about the acceptance or rejection of the organ.

KEY-WORDS: Hepatitis; Methyldopa; Liver failure, acute; Liver transplantation; Schistosomiasis. 
Zerbini T, Siqueira SAC. Relato de caso: Óbito após transplante de fígado esquistossomótico.

\section{REFERÊNCIAS}

1. Mies S. Transplante de fígado. Rev Assoc Med Bras. 1998;44(2):127-34.

2. Garcia JHP, Vasconcelos JBM, Brasi IRC, Costa PEG, Vieira RPG, Moraes MO. Transplante de fígado: resultados iniciais. Rev Col Bras Cir. 2005;32(2):100-103.

3. Brasil. Ministério da Saúde. Dados estatísticos de transplantes. Disponível em: http://portal.saude. gov.br/portal/saude.

4. Williams R, Wendow J. Indications for orthotopic liver transplantation in fulminant liver failure. Hepatology. 1994;20(Suppl):5-10.

5. Benhamou JP. Indications for liver transplantadion in primary biliary cirrhosis. Hepatology. 1994;20(Suppl):11-3.

6. Harrison J, McMaster P. The role of orthotopic liver transplantation in the management of sclerosing cholangitis. Hepatology. 1994;20(Suppl):14-9.

7. Boyaciyan K, Marcus PAF, Vega CEP, Barbosa SA, Pazero LC. Mortalidade materna na cidade de São Paulo de 1993 a 1995. Rev Bras Ginecol Obstet. 1998;20(1):13-8.

8. Cecatti JG, Albuquerque RM, Hardy E, Faúndes A. Mortalidade materna em Recife: causas de óbitos maternos. Rev Bras Ginecol Obstet. 1998;20(1):711.

Recebido em: 23/06/2010

Aprovado em: 23/08/2010
9. Tanaka ACA, Mitsuiki L. Estudo da magnitude da mortalidade materna em 15 cidades brasileiras. São Paulo: USP/FSP; 1999.

10. Peraçoli JC, Parpinelli MA. Síndromes hipertensivas da gestação: identificação de casos graves. Rev Bras Ginecol Obstet. 2005;27(10):627-34 .

11. Rudge MVC, Vasconcellos MJA. Diabete e hipertensão na gravidez: manual de orientação da FEBRASGO. São Paulo: Ponto; 2004

12. Bartlett AS, et al. The natural history of acute histologic rejection without biochemical graft dysfunction in orthotopic liver transplantation: a systematic review. Liver Transpl. 2002;8:1147-53.

13. Secretaria de Estado da Saúde. Sistema Estadual de Transplantes. Protocolo sobre o doador de múltiplos órgãos [citado em 10 ago. 2010]. Disponível em: http://www.saude.sp.gov.br/admin.

14. Katz N, Peixoto SV. Análise crítica da estimativa do número de portadores de Esquistossomose Mansoni no Brasil. Rev Soc Bras Med Trop. 2000;33(3):303-8.

15. Hoare M, Gelson WTH, Davies SE, Curran M, Alexander GLM. Hepatic and intestinal schistosomiasis after orthotopic liver transplant. Liver Transplant. 2005;11(12):1603-7.

16. Pannegeon V, Masini JP. Schistosoma Mansoni infection and liver graft. Semin Transplant. $2005 ; 287$. 